\title{
Arabidopsis Pollen Tube Germination Protocol
}

Xiyan $\mathrm{Li}^{*}$

Department of Genetics, Stanford University, Stanford, USA

*For correspondence: lixiyan@stanford.edu

[Abstract] This method uses a PEG-supplemented liquid solution to germinate separated Aradidopsis pollen. It thus eliminated the need for humidity control.

\section{Materials and Reagents}

A. Plant growth

1. Stratify surface-sterilized seeds on $1 x$ Johnson's medium at $4{ }^{\circ} \mathrm{C}$ for at least 3 days to synchronize the flowering time. Transfer the plates to growth chamber with sufficient illumination (e.g. 12-16 h light/day, growth chamber on the 2 nd or $3 \mathrm{rd}$ floor is OK).

2. 1 week seedlings are transferred to soil pots. I usually grow up to 8 seedlings per standard pot. Mutant and wildtype should be put side by side to avoid position effect in the growth chamber.

3. Water the plants twice a week (Tuesday and Friday, for example), and apply $0.5 x$ Johnson's medium once every other week. The plants may begin to flower 3-4 weeks after transferring. The fresh flowers on the first inflorescence will be good for pollen germination experiments (note: The time to pick flowers is very critical).

B. Preparation of germination plates

Prepare germination medium plates as following (Fan et al., 2001)

\begin{tabular}{|l|l|l|l|}
\hline & Stock & Final Conc. & V stock/40 ml \\
\hline $\begin{array}{l}\text { MES-Tris (pH 5.8 adjusted } \\
\text { with Tris base) }\end{array}$ & $200 \mathrm{mM}$ & $5 \mathrm{mM}$ & $1 \mathrm{ml}$ \\
\hline $\mathrm{KCl}$ & $1 \mathrm{M}$ & $1 \mathrm{mM}$ & $40 \mu \mathrm{l}$ \\
\hline $\mathrm{MgSO}_{4}$ & $0.5 \mathrm{M}$ & $0.8 \mathrm{mM}$ & $64 \mu \mathrm{l}$ \\
\hline Boric acid & $100 \mathrm{mM}$ & $1.5 \mathrm{mM}$ & $600 \mu \mathrm{l}$ \\
\hline $\mathrm{CaCl}_{2}$ & $0.5 \mathrm{M}$ & $10 \mathrm{mM}$ & $800 \mu \mathrm{l}$ \\
\hline Sucrose & & $5 \% \mathrm{w} / \mathrm{v}$ & $2 \mathrm{~g}$ \\
\hline PEG4000 & & $15 \% \mathrm{w} / \mathrm{v}$ & $6 \mathrm{~g}$ \\
\hline
\end{tabular}


Notes:

a. Mix well when add $\mathrm{MgSO}_{4}$ and $\mathrm{CaCl}_{2}$ to avoid precipitation.

b. $5 \mathrm{mM}$ Ca might be better than $10 \mathrm{mM}$ sometimes.

c. You can make pollen germination medium (PGM) without Ca, use it to prepare the pollen resuspension. The unwanted germination before time 0 can be avoided this way.

\section{Equipment}

1. Incubator with humidity control or saturated humidity

2. Nikon microscope

3. Scion Image (free download from NCBI website)

4. 8-well chamber (Lab-Tek International, catalog number: 155411 or VWR International, catalog number: 43300-774)

\section{Procedure}

1. Collect $20-50$ freshly opened flowers (stage $13-15$, in which the long filaments are just level with stigma and petals) in $1.5 \mathrm{ml}$ tube, let dry on RT for $0.5 \mathrm{~h}$ (tube cap opened).

Note: You can remove all open flowers from the plant 16-24 $h$ before the pollen experiment. By this way just simply pick all flowers without spending time on identifying right stage (warning: wounding response may happen). Flowers picked in the morning are better than in afternoon.

2. Add $1 \mathrm{ml}$ germination medium to submerge the flowers. Vortex at maximal speed for 1 $\min$.

3. Concentrate the pollens by $500 \times \mathrm{g}$ for $5 \mathrm{~min}$, at RT centrifuge $(3,000 \mathrm{rpm}$ on minicentrifuge). Carefully remove the supernatant and floating flower residues, resuspend the pollen pellet in $1 \mathrm{ml}$ germination medium (with $\mathrm{Ca}$ if you used -Ca PGM previously) by vortex.

4. Use $10 \mu \mathrm{l}$ suspension for pollen amount estimation and purity check under light microscope (typical yield of $10 \mu \mathrm{l}$ from 20 flowers is somewhere 2,000-5,000 grains).

5. Germinate the pollen grains at $25-28{ }^{\circ} \mathrm{C}$ for $6 \mathrm{~h}$ or over night in the chambers of a chambered coverlip (200 $\mu$ l pollen suspension/ 8-well chamber); no agitation.

6. Take photos of the germinated tubes using 10x lens on Nikon microscope (inverted is better). Since the tube is transparent, phase contrast will give good pictures. 
7. Analyze the tube germination (rate and length) using Scion Image. A normal distribution is expected for each population of pollen tube length, the $P$ value should be less than 0.05 for student's test.

\section{$\underline{\text { References }}$}

1. Fan, L. M., Wang, Y. F., Wang, H. and Wu, W. H. (2001). In vitro Arabidopsis pollen germination and characterization of the inward potassium currents in Arabidopsis pollen grain protoplasts. J Exp Bot 52(361): 1603-1614.

2. Lalanne, E., Honys, D., Johnson, A., Borner, G. H., Lilley, K. S., Dupree, P., Grossniklaus, U. and Twell, D. (2004). SETH1 and SETH2, two components of the glycosylphosphatidylinositol anchor biosynthetic pathway, are required for pollen germination and tube growth in Arabidopsis. Plant Cell 16(1): 229-240.

3. Mouline, K., Very, A. A., Gaymard, F., Boucherez, J., Pilot, G., Devic, M., Bouchez, D., Thibaud, J. B. and Sentenac, H. (2002). Pollen tube development and competitive ability are impaired by disruption of a Shaker $\mathrm{K}(+)$ channel in Arabidopsis. Genes Dev 16(3): 339-350.

4. Thorsness, M. K., Kandasamy, M. K., Nasrallah, M. E. and Nasrallah, J. B. (1993). Genetic ablation of floral cells in Arabidopsis. Plant Cell 5(3): 253-261. 